\title{
Pós-graduação em Educação Física UEM/UEL: experiências e desafios de um programa associado
}

\section{Graduate program in physical education: experiences and challenges of a program offered in association by Universidade Estadual de Londrina and Universidade Estadual do Maringá}

\section{Jeane Barcelos Soriano ${ }^{1}$ \\ Larissa Michelle Lara ${ }^{2}$}

1. DEF- CEFE - Universidade Estadual de Londrina, PR, Brasil.

2. DEF - CCS - Univesidade Estadual de Maringá, PR, Brasil.

\begin{abstract}
Resumo
O texto apresenta o Programa de Pós-Graduação Associado em Educação Física UEM-UEL, relatando experiências e desafios do primeiro programa associado em Educação Física do país. Tal intuito dá-se no sentido de contribuir com a ampla visibilidade do Programa, disponibilizando informações para que profissionais de diferentes regiões possam conhecer suas áreas de concentração, linhas de pesquisa, professores participantes e desenvolvimento de modo geral, ampliando o acesso à informação e ao conhecimento.

Palavras-chave: Educação Física; formação em pós-graduação; programas de pós-graduação.
\end{abstract}

\section{ENDEREÇOPARA CORRESPONDÊNCIA}

\section{Jeane Barcelos Soriano}

Centro de Educação Física e Esporte

Universidade Estadual de Londrina

Rod. Celso Garcia Cid, Km 380 (Pr 445)

Caixa Postal 6001

Londrina, PR - 86051-990

jeane@uel.br

$$
\begin{array}{ll}
\text { - Recebido: } & 28 / 06 / 2011 \\
\text { - Re-submissão: } & 21 / 09 / 2011 \\
\text { - Aceito: } & 24 / 09 / 2011
\end{array}
$$

\begin{abstract}
The text presents the Graduate Studies in Physical Education Associate UEM-UEL, reporting experiences and challenges with the first graduate course associated in Physical Education in the country. This takes place in order to contribute to the high visibility of the program, providing information for professionals coming from different regions to meet their areas of concentration, research areas, participating teachers and development in general, expanding access to information and knowledge.

Keywords: Physical Education, graduate education, graduate programs
\end{abstract}




\section{INTRODUÇÃO}

A criação e o desenvolvimento de um Programa de Pós-Graduação requer a concentração de esforços múltiplos de atores sociais engajados em formação e produção de conhecimento. Sua sustentabilidade exige do corpo docente motivação, disciplina, desempenho intelectual e atuação coletiva suficientes para o cumprimento de exigências próprias do sistema da pós-graduação, que demanda responsabilidade para com os investimentos públicos destinados ao campo da formação e da pesquisa em nível stricto sensu.

A reconfiguração do próprio campo da graduação, que passa, na década de 1990, a intensificar a relação entre ensino e pesquisa, fez com que o Departamento de Educação Física da Universidade Estadual de Maringá (DEF-UEM) e o Centro de Educação Física e Esporte da Universidade Estadual de Londrina (CEFE-UEL) envidassem esforços para a qualificação e o aprimoramento acadêmico, científico e pedagógico de recursos humanos. Tal iniciativa resultou no início do funcionamento, em 2006, do primeiro programa de pós-graduação associado em Educação Física do país, em nível de mestrado.

Dentro de uma política federal que desenhou ações para o avanço do Sistema Nacional de Pós-Graduação (BRASIL, 2004), o corpo docente da UEL e da UEM empenhou-se na direção de realizar uma proposta que, ao mesmo tempo em que potencializasse a instalação de um programa de pós-graduação na região, também permitisse a compreensão mútua das diferenças institucionais e de organização político-pedagógica. Esses aspectos fizeram com que, gradativamente, o Programa pudesse ser aprimorado em termos de formação, organização da estrutura curricular e produção intelectual, elementos essenciais que deram sistematicidade ao mestrado recém-criado, além de contribuir com sua visibilidade nacional.

Reconhecidos avanços foram desencadeados desde a implantação do Programa Associado tais como: a) aumento do número de grupos de estudo e pesquisa; b) incremento do número de projetos cadastrados e subsidiados financeiramente por agências de fomento; c) melhoria da infraestrutura para a pesquisa; d) ampliação do número de bolsas de iniciação científica; e) melhoria da produtividade em pesquisa; f) aumento da disseminação de artigos em periódicos nacionais e internacionais; g) estabelecimento de parcerias entre estudantes, pesquisadores, laboratórios e grupos de estudo e pesquisa, dentro e fora das respectivas Universidades. Esse quadro, por sua vez, remeteu o corpo docente a pensar em metas mais arrojadas e reescalonar seus objetivos. Desse modo, buscaram-se ações que possibilitassem o intercâmbio entre pesquisadores, promovessem o crescimento sustentável com a implantação de mais uma área de concentração e, em decorrência, fortalecesse a produção de conhecimento com recorte da área de humanas. Por conseguinte, tais iniciativas são denotativas da orientação por uma perspectiva ampliada do que se entende fundamental para preparação de recursos humanos para docência e pesquisa.

A partir de 2010, iniciou-se a implantação de uma política de gestão integrada, entre a UEM e a UEL, de aspectos administrativos, orientação acadêmica e distribuição de recursos, amplamente compartilhados pelas respectivas coordenações locais, permitindo transparência e qualidade no processo de decisões tomadas intra e interinstitucionalmente.

A aprovação da Proposta de abertura do curso de doutorado, a partir de 2011, demonstra o estágio em que o PPGEF-UEL/UEM se encontra em seu processo de consolidação e diversificação de parcerias nacionais e internacionais, fomen- tando novas frentes para o desenvolvimento da produção de conhecimento e formação de recursos humanos.

No intuito de apresentar o Programa de Pós-Graduação Associado em Educação Física UEM-UEL, em suas experiências e desafios, o texto apresenta o processo histórico de surgimento do Programa, bem como sua organização, desenvolvimento e gestão. Com isso, entendemos ser possível disponibilizar informações que possam orientar diferentes profissionais quanto a elementos elucidativos acerca de um espaço de qualificação da formação.

\section{Breve histórico da constituição do PPGEF Associado} em Educação Física UEL/UEM

Trazer parte do contexto histórico de surgimento e desenvolvimento do PPGEF é reconhecer que sua formação não se dá desvinculada de tensões constitutivas. Há encontros e desencontros que marcam um programa na tentativa de afinar relações interpessoais e institucionais em meio às diferenças que lhes são próprias. Daí que o entendimento do processo histórico auxilia na visualização das características atuais que definem determinada estrutura formativa e de pesquisa

Na direção do balanço e reflexão sobre formatos inovadores e atendimento de demandas diferenciadas previstos como política do SNPG (BRASIL, 2004), iniciaram-se, em 2004, os diálogos entre o Departamento de Educação Física da Universidade Estadual de Maringá (UEM) e o Centro de Educação Física e Esporte da Universidade Estadual de Londrina (UEL), para elaboração da proposta de implantação do Programa de Pós-Graduação, com o curso de mestrado. A situação, naquele momento, indicava a existência de um pequeno número de projetos de pesquisa cadastrados, oficialmente, pelos proponentes; um número reduzido de bolsas de iniciação científica; um pequeno número de grupos de estudo e pesquisa, em formação ou em fase de consolidação; uma capacidade de captação de recursos ainda tímida; e uma produção intelectual que dava sinais de crescimento. Os fatores diferenciadores, no entanto, eram a característica do corpo docente, em sua maioria, recém-doutores, originários de programas tradicionais da área e compromissados com suas instituições, mas também contou-se com doutorandos na última etapa de seus cursos. Além disso, levou-se em conta a infra-estrutura física e a história das duas instituições como formadoras de recursos humanos para a área de Educação Física, em nível de graduação.

Cerca de 20 docentes da UEM e da UEL passaram a se envolver com a proposta, mas somente 11 doutores, cinco da UEM e seis da UEL, atendiam naquele momento às condições mínimas exigidas pela CAPES para a criação de novos programas de Pós-Graduação stricto-sensu em Educação Física. Portanto, esse foi o grupo que compôs a equipe de docentes permanentes da proposta, sendo a coordenação do Programa exercida pelos professores Edilson Serpeloni Cyrino (UEL) e José Luiz Lopes Vieira (UEM), os quais gestaram o Programa por quatro anos. Apenas em setembro de 2009 houve mudança de coordenação na UEM, assumindo a gestão do Programa a professora Larissa Lara e, em junho de 2010, a professora Jeane Barcelos Soriano, pela UEL e, atualmente, a coordenação na UEL encontra-se sob a responsabilidade do professor Marcos Polito.

O desenho inicial do Programa, em 2006, foi idealizado a partir de uma única área de concentração, denominada de Estudos do Movimento Humano, a qual contemplava três linhas de pesquisa, de acordo com as características do corpo docente envolvido: a) Aspectos fisiológicos do exercício físico; b) Aquisição e desempenho de habilidades motoras; c) Ativi- 
dade física relacionada à saúde. A proposta foi apresentada à CAPES, no ano de 2005, que a recomendou em sua primeira submissão, sendo criado, dessa maneira, o primeiro Programa de Pós-Graduação Associado em Educação Física, em nível de mestrado, no Brasil.

No segundo ano de funcionamento, em 2007, foi criada a quarta linha de pesquisa denominada "Formação e intervenção em educação física", que viria a abrir espaço para o ingresso de discentes com interesse acadêmico em pesquisas que incursionassem pelas ciências humanas e sociais, indicando a necessidade de induzir e consolidar a produção de conhecimento nessa dimensão. A abertura dessa linha potencializou a proposição e criação da segunda área de Concentração no Programa, que contou com credenciamento de novos docentes, os quais de maneira colaborativa têm se responsabilizado pela preparação e reflexão acerca de questões de ordem filosófica e epistemológica junto à estrutura curricular vigente.

Com o processo de discussão interna e amadurecimento acadêmico foram propostas ações programáticas. Professores renomados na área e com experiência em análises de propostas de programas foram convidados para dialogar com os docentes de modo a realizar avaliação e reflexão sobre o resultado do primeiro envio da proposta de Doutorado encaminhada à Capes, em 2009, em que o curso não foi recomendado. Tal colaboração culminou no engajamento do corpo docente num projeto coletivo para realizar reformulações que viessem a refletir o que o Programa realmente era.

Um plano de trabalho foi colocado em prática, com a participação de todos os docentes, os quais entenderam que a conjuntura atual seria favorável para o envio do APCN. Essa conjuntura foi sinalizada por aspectos como: visita institucional ao programa pela Comissão de Avaliação da CAPES, potencialidade de abertura de novos cursos de Doutorado junto à área 21, alta produtividade do corpo docente, amadurecimento do corpo docente em relação ao Programa em si, avaliação da proposta por consultores externos, bem como crescimento exponencial da segunda área de concentração.

Foram feitas revisões conceituais de áreas e linhas de pesquisa no sentido de uma nomenclatura que refletisse o que o Programa era. Considerando os apontamentos do
CTC-CAPES, explicitados na ficha de avaliação da proposta de 2009, e observando-se as orientações dos avaliadores da CAPES em visita institucional, o PPGEF Associado passou a funcionar com as seguintes as áreas de concentração: a) Desempenho humano e atividade física; b) Práticas sociais em Educação Física, que por sua vez compuseram a proposta do Doutorado. Ainda, no mês de setembro de 2010, o Programa recebeu a nota 4 em avaliação trienal, o que contribuiu para aumentar as expectativas em relação ao doutorado. Em novembro de 2010, a proposta foi aprovada pela CAPES, cuja primeira turma foi iniciada em março de 2011, contando com 12 professores orientadores e 12 vagas.

\section{Organização e desenvolvimento do PPGEF}

O PPGEF Associado UEM/UEL, com duas áreas de concentração, propõe a articulação da produção de conhecimento em cinco linhas de pesquisa. Desse modo, a AC1 - Desempenho Humano e Atividade Física articula três linhas que buscam a investigação das estruturas, processos e mecanismos vinculados ao estudo do desempenho humano e da atividade física e a AC2 - Práticas Sociais em Educação Física, por sua vez, busca a investigação das estruturas, processos e representações vinculados ao estudo das práticas sociais em educação física, organizando-se em duas linhas, conforme pode ser observado na Figura 1, que apresenta as áreas e respectivas linhas de pesquisa.

A AC1, com suas linhas de pesquisa, volta-se para o estudo: a) das respostas fisiológicas e metabólicas do organismo em situações de exercício agudo ou crônico em diferentes populações; b) de programas de atividade física em diversas populações, com emprego de métodos e técnicas de avaliação de indicadores relacionados à saúde; c) das características psicossociais e motoras, bem como da aplicação das teorias de mudança de comportamento, mecanismos de aquisição e organização no desempenho de habilidades.

A AC2 volta-se para análise: a) dos processos de formação em educação física a partir de suas especificidades na educação brasileira, bem como dos aspectos teórico-metodológicos da prática docente e constituição da intervenção profissional; b) da produção de conhecimento em educação

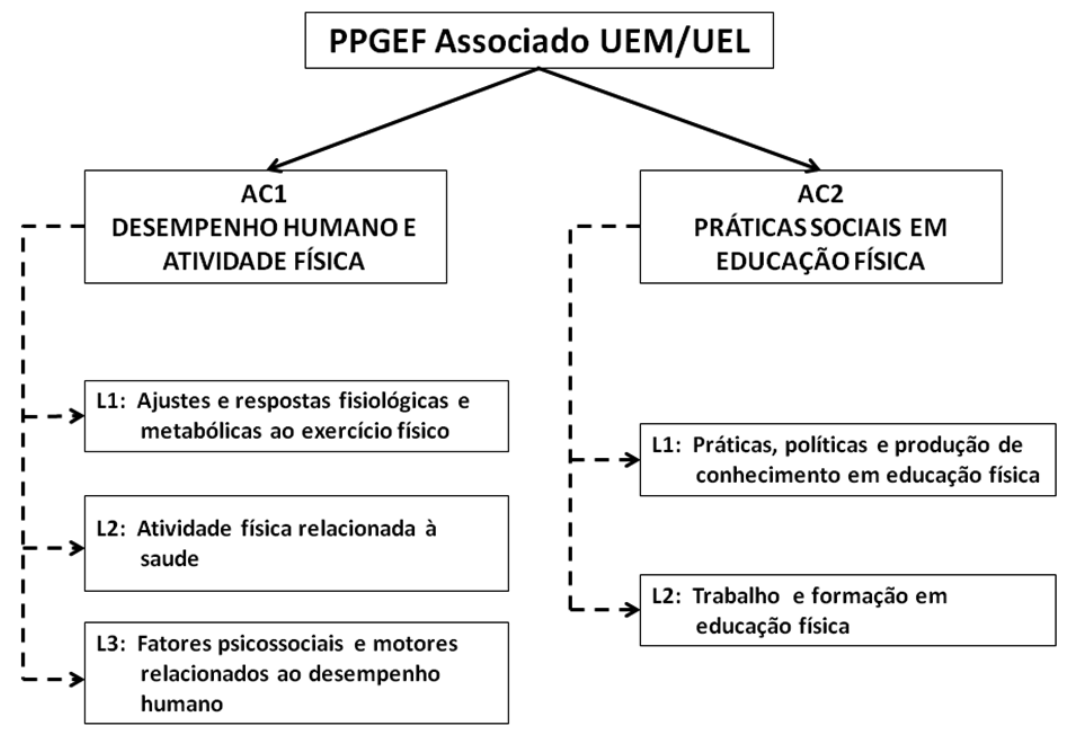


física, esporte, lazer, e relações em que as práticas, as políticas e a produção encontram-se inscritas.

No Quadro 1 apresentamos a distribuição dos docentes conforme vinculação às Áreas de Concentração do programa. vimento

Gestão do Programa Associado: ações de desenvol-

Ao discorrer sobre os dilemas do coordenador de Programas de Pós-graduação em Educação, Bianchetti (2009) adverte para o fato de que ninguém faz curso para ser coordenador, sendo essa uma das funções de maior exigência institucional, em que os bônus são socializados e os ônus individualizados na figura do gestor. Nesse sentido, o autor questiona: "Como é possível ser democrata, aberto, querer discutir, co-ordenar [...] trabalhando na tensão entre essa opção, esse desejo e o pertencimento a um sistema [...]"? (p. 26). Ainda, em relação aos professores/parceiros da pós-graduação, interroga: "Como cada professor, individualmente e no coletivo dos Programas se coloca, se insere, adere, colabora, resiste à forma de organização e funcionamento dessa instituição"? (p. 27). Tais reflexões ganham ressonância em nossa experiência de gestão no PPGEF, uma vez que também entendemos, como Bianchetti, que o "coordenador é um solitário" (p. 65), uma vez que trabaIha pelo coletivo, mas acaba tendo pouco apoio e envolvimento desse coletivo; é pouco solidário porque é cobrado e tem a função de cobrar, função esta nem sempre compreendida. Daí, novamente, comungarmos do pensamento de Bianchetti quando adverte que: "Quanto mais professores assumirem a função, maior será o grupo daqueles que terão a compreensão de tudo o que envolve a organização, o funcionamento e os objetivos de um Programa" (p. 81).

A gestão de um Programa Associado é marcada por dilemas e desafios semelhantes a outras gestões de Programas não associados, acrescido de situações particulares. Entre as dificuldades que o PPGEF enfrentou e enfrenta podemos citar as diferenças institucionais, mesmo entre duas universidades estaduais, que fazem com que esforços adicionais sejam empreendidos no sentido de promoção da associação, impactando a gestão, o andamento e o processo decisório de ações no cotidiano do programa. Assim, para que um programa funcione verdadeiramente de forma associada e não apenas como um congregado de instituições, as coordenações acabam tendo que se desdobrar para contornar situações de pouca disposição de adaptabilidade das próprias Universidades, com relação às necessidades da associação que, muitas vezes, estão no interstício das rotinas e procedimentos administrativos habituais.

Devemos acrescentar também que a despeito do PPGEF ter sido proposto na esteira do estímulo das parcerias e consórcios por parte do SNPG (BRASIL, 2004), considera-se ainda incipiente a abordagem e logística do atendimento de suas particularidades, demandas e aferição de sua qualidade por parte da CAPES'. Esses aspectos representaram um aprendizado do "funcionamento da associação", os quais devem, inerentemente, contar com a motivação diária para o diálogo que respeite as especificidades sem desconsiderar aquilo que cada instituição entende ser melhor para si.

Não obstante, devem-se destacar algumas das ações desenvolvidas na direção de um sistema que fosse mais eficaz para o alcance dos objetivos do PPGEF, como missão institucional, educacional e espaço para produção de conhecimento. Assim, foi fundamental a busca de se identificar a capacidade de diálogo construída entre as duas instituições. Esse aspecto promoveu a unificação de muitas das ações que eram isoladas e, muitas vezes, contraditórias em cada instituição, a exemplo da página eletrônica ${ }^{2}$, do regulamento para o processo seletivo de bolsas de demanda social, dos valores das taxas de inscrição para os processos seletivos, entre outros. A dinâmica cotidiana da pós-graduação também foi priorizada,

1 Em 2011, pela primeira vez, o Coleta-Capes foi preenchido conjuntamente por ambas as instituições, com divisão de funções por ambas as coordenações. Esse foi um passo importante para o preenchimento ampliado e cuidadoso das informações próprias a cada instituição, e do reconhecimento de problemas que precisam ser corrigidos no sentido de qualificar as ações.

2 Página do Programa disponível em http://www.uel.br/pos/ ppgef.

\section{Desempenho humano e atividade física}

Fábio Yuzo Nakamura Marcos Doederlein Polito Jefferson Rosa Cardoso Edilson Serpeloni Cyrino Leandro Ricardo Altimari Luiz Cláudio Reeberg Stanganelli Fabiana Andrade Machado Paulo Cezar de Freitas Mathias Solange Marta Franzói de Moraes Wilson Rinaldi Arli Ramos de Oliveira
Marcia Greguol

Hélio Serassuelo Junior

Enio Ricardo Vaz Ronque

Nelson Nardo Júnior Inara Marques

Victor Hugo Alves Okazaki Christi Noriko Sonoo José Luis Lopes Vieira Lenamar Fiorese Vieira Pedro Paulo Deprá Vanildo Rodrigues Pereira

\section{Práticas sociais em educação física}

Elza Margarida de M. Peixoto Jeane Barcelos Soriano Larissa Michelle Lara
Giuliano Gomes de Assis Pimentel leda Parra Barbosa Rinaldi Amauri A. Bássoli de Oliveira 
com a viabilização institucional de transporte para levar os alunos de uma instituição para cursar disciplinas na outra.

O regulamento e a estrutura curricular, por sua vez, também foram modificados, sendo uma das conquistas a criação de disciplinas de núcleo comum em que os alunos de diferentes linhas compartilham os mesmos conhecimentos e debatem ideias, ampliando a sua formação para além do âmbito da pesquisa acadêmica, como: epistemologia e educação física; metodologia do ensino superior; metodologia da pesquisa científica; educação física e universidade. Ainda, na modalidade de disciplina, desenhou-se a possibilidade de se propor Tópicos Especiais, disciplina que permite aos professores do programa ou convidados contribuírem com assuntos que são importantes para a formação, possibilitando a inclusão de subtópicos conforme necessidade de inserção e variação temática. Por fim, com intuito de estimular a experimentação do processo de produção de conhecimento e orientação, como parte fundamental da preparação em pós-graduação, foram planejadas, na estrutura curricular, estratégias de cumprimento de créditos que propiciassem a valorização de vivências em relação a: a) atividades de orientação e tutoria; b) organização e implementação das atividades de grupo de estudos; c) produção de textos, apresentação de trabalhos em eventos e submissão dos produtos de pesquisa em periódicos científicos.

A exemplo do que acontece em um Programa convencional, no PPGEF Associado UEL/UEM há também dificuldades relacionadas à motivação do coletivo de professores para o envolvimento cotidiano com a pós-graduação. A diversidade de pensamentos acerca da compreensão de um Programa como "mais" ou "menos" pautado pelo produtivismo acadêmico também é um dos pontos polêmicos, geralmente externados em debates em torno das deliberações cotidianas e de planejamento de médio e longo prazo entre professores de áreas distintas, o que envolve, também, reflexões sobre a disseminação internacional. Como lembram Sguissardi e Silva Júnior (2009, p. 225-6), "a avaliação acadêmica centrada na publicação e com ênfase nas publicações internacionais parece apresentar uma contradição visível, entre várias outras". Os autores se referem a pesquisas financiadas pelo fundo público que atendem mais a demandas externas do que a nacionais, bem como a pesquisas na área de saúde pública e educação no país que podem não ser prioridade de publicação no exterior, trazendo consequências paras as áreas e para os Programas. Portanto, reconhecer esses problemas e perceber as singularidades do corpo docente e suas especificidades de produção é um dos impasses que tem suscitado debate e que merecem ser reconhecidos como algo salutar para o desenvolvimento da própria área.

Em relação aos esforços empreendidos em termos de mobilidade de estudantes e intercâmbio com IES no país e no exterior, o Programa ainda tem muito por desenvolver. Há iniciativas de orientadores em enviar pós-graduandos para participação em eventos no exterior, culminando com a ampliação de estadia para inserção em laboratórios. Contudo, ainda é carente a mobilidade estudantil, por exemplo. Com o doutorado, esperamos intensificar a participação de pós-graduandos no exterior para fazer "sanduíche", além de potencializar a mobilidade de estudantes junto a outras IES no país e exterior.

A saída de docentes para capacitação em estágios de pós-doutoramento é outra ação conjeturada e que começou a ser efetivada em 2008. O Programa prevê que anualmente devam ser efetivadas novas saídas de professores do corpo docente permanente para estágios em Centros de Excelência em Pesquisa no exterior. Essa ação tem como principais objetivos, além da melhoria da formação do quadro docente, o estabelecimento de convênios entre laboratórios e instituições, o desenvolvimento de projetos conjuntos, o intercâmbio entre docentes e discentes e a melhoria da inserção internacional do Programa, proporcionando maior visibilidade. Ainda nessa direção, iniciativas de parcerias internacionais têm sido estabelecidas por integrantes do corpo docente do Programa com pesquisadores e centros de pesquisas no exterior. Alguns docentes estão visitando países no sentido de estabelecer intercâmbio e buscar parcerias de pesquisa, em especial, com a Colômbia, País de Gales, Portugal e Canadá. Cursos internacionais também têm contribuído nessa direção, tendo um deles resultado em intercâmbio discente em laboratório de Pesquisa no exterior.

Os fomentos institucionais também representam conquistas, uma vez que eles impulsionam a estruturação dos laboratórios e, com isso, dinamizam a produção dos grupos de pesquisa, alavancando as produções acadêmicas e potencializando-as em termos de inovação. Uma das linhas de ação assumidas pelo PPGEF-UEM/UEL como fundamental para seu crescimento e consolidação foi a negociação e crescente participação do Programa Associado, em ambas as universidades, junto às equipes de planejamento e consecução de propostas institucionais das Pró-Reitorias de Pesquisa e Pós-Graduação, para captação de recurso em Editais direcionados às instituições públicas, tais como o CT-INFRA-FINEP - Fundo de Infra-estrutura, CT-INFRA ABRUEM-FINEP e Pró-Equipamentos - CAPES. Essa ação possibilitou a captação de recursos para equipamentos fundamentais à implantação de linhas de investigação e consequente projeção internacional, tornando os protocolos e tratamento técnico instrumental para as coletas mais robusto e consistente, dando competitividade para inserções dos artigos em periódicos internacionais de impacto.

Com essa mudança de perspectiva no trato com a forma de captação, o Programa migra de uma dinâmica individualista de responsabilização pelo insucesso ou sucesso em editais de fomento para um cenário de projeção e trabalho em equipe, no qual, na soma, o grupo torna-se exponencialmente competitivo e potencialmente mais atraente para justificar linhas ampliadas de investigação e de interação com pesquisadores de outras unidades universitárias.

O PPGEF tem seu desenvolvimento pautado em esforços coletivos daqueles que o integram e do apoio institucional que tem procurado atender às suas solicitações. As transformações são gradativas, mas recorrentes. Cada conquista é vista como passo importante de um projeto maior, que implica no aprimoramento das atividades da pós-graduação e em sua qualificação, considerando a condição humana de todos que integram esse sistema.

\section{CONSIDERAÇÕES FINAIS}

A incursão pelo PPGEF Associado UEM-UEL, nessa seção, deu-se no intuito de trazer informações, embora sinteticamente, sobre elementos que compõem o cotidiano do Programa, assim como compartilhar avanços, conquistas e processos de construção de cogestão da complexa estrutura de uma associação de instituições preocupadas com a preparação de recursos humanos para pesquisa, com a produção de conhecimento e com o ensino superior. O texto apresenta o PPGEF, relatando experiências e desafios do primeiro programa associado em Educação Física do país, contribuindo com 
informações sobre sua estrutura organizacional.

Ao trazermos informações sobre o Programa, apontamos para seus avanços e limites, registrando o momento histórico em que nos situamos. Talvez, possamos, daqui a alguns anos, olhar para esse texto como registro da memória do que o programa viveu, já atendendo a muitas das ações que aqui se colocam como perspectivas. Para tanto, muitas frentes precisam ser vencidas, exigindo dos gestores e professores serenidade, capacidade de manter ações colaborativas interinstitucionais e compromisso para com a pós-graduação brasileira como um todo.

Não é segredo que o PPGEF Associado UEM/UEL também se vê na realidade dos problemas enfrentados pelos programas em processo de consolidação, entre os quais se encontra o gerenciamento dos escassos recursos disponíveis para se viabilizar o cotidiano da pós-graduação com bancas, convidados, coleta de dados, eventos, entre outros, o que faz com que o próprio processo seletivo seja pensado, muitas vezes, a partir de um planejamento sustentável que dê conta da oferta de um número de vagas compatível com limitantes financeiros, garantindo as condições mínimas necessárias para a acolhida do pós-graduando. Esse é um limitador a se considerar, sobretudo num programa associado que reserva demandas e necessidades diferenciadas, mas responde às mesmas exigências relacionadas à avaliação, funcionamento e excelência.

Com o aumento desse tipo de modalidade (associação) entre os programas reconhecidos pela CAPES, entendemos ser urgente e necessário estabelecer-se o estudo de mecanismos que contribuam academicamente para o desenvolvimento sustentável desses programas a partir de seu papel social junto à pós-graduação e que os auxiliem financeiramente em sua própria sobrevivência. Esclarecemos que esse espaço, que se consolida pela democratização de informações sobre pós-graduação, também é marcadamente um espaço políti$\mathrm{co}$, em que reivindicações de melhorias para a gestão adequada e qualitativa dos programas de pós-graduação no Brasil precisam ser publicizadas.

Por fim, ressaltamos que a construção colaborativa desse texto pelas autoras em questão revive e ressalta os momentos de gestão compartilhada em que a associação foi efetivamente valorizada, intensificada por ações institucionais que encontraram ressonância e que amadureceram com respeito e diálogo. A posição assumida pela coordenação no tocante à qualificação da pós-graduação, partindo do pressuposto de que "produzir muito não é sinônimo de produzir bem", implementando reformulações que culminassem em uma formação ampliada de modo a contemplar não só a especificidade das linhas, mas a organização política e epistemológica da área são alguns dos traços dessa gestão. Sem profetizar, talvez seja o aceno para aquilo que a pós-graduação brasileira precisará focar, num curto espaço de tempo, que a qualidade daquilo que se produz e não o quanto se produz, poderá potencializar a formação de profissionais capazes de discutir o micro (sua especificidade de formação), mas notadamente o macro (a área em suas questões políticas, acadêmicas, epistemológicas). Isso, certamente, faz a diferença na formação de mestres e doutores, no pleno sentido dos termos, o que aumenta nossa responsabilidade e nosso compromisso.

\section{Contribuição das Autoras}

As autoras responsabilizam-se integral e igualmente pela consecução e organização do artigo como um todo, sendo sua estruturação realizada por ambas as partes.

\section{REFERÊNCIAS}

1. Bianchetti L; Sguissardi V. (Org.). Dilemas da pós-graduação: gestão e avaliação. Campinas, SP: Autores Associados, 2009.

2. Daolio J. O ser e o tempo da pesquisa sociocultural em educação física. Revista Brasileira de Ciências do Esporte 2007; 29: 49-60.

3. Sguissardi V; Silva Júnior JR. Trabalho intensificado nas federais: pós-graduação e produtivismo acadêmico. São Paulo: Xamã, 2009.

4. BRASIL. Plano nacional de pós-graduação (PNPG) 2005-2010. Ministério da Educação e Coordenação de Aperfeiçoamento de Pessoal de Nível Superior - CAPES, 2004. Disponível em: <http://www.capes.gov.br/images/stories/download/editais/PNPG_2005_2010.pdf>. Acesso em: 23 jun. 2010. 